\title{
Dynamic changes in cellular infiltrates with repeated cutaneous vaccination: a histologic and immunophenotypic analysis
}

\author{
Jochen T Schaefer 2,3,4, James W Patterson 2,3,4, Donna H Deacon ${ }^{1,2}$, Mark E Smolkin ${ }^{5}$, Gina R Petroni ${ }^{5}$, \\ Emily M Jackson ${ }^{2}$, Craig L Slingluff Jr $r^{1,2^{*}}$
}

\begin{abstract}
Background: Melanoma vaccines have not been optimized. Adjuvants are added to activate dendritic cells (DCs) and to induce a favourable immunologic milieu, however, little is known about their cellular and molecular effects in human skin. We hypothesized that a vaccine in incomplete Freund's adjuvant (IFA) would increase dermal Th1 and Tc1-lymphocytes and mature DCs, but that repeated vaccination may increase regulatory cells.

Methods: During and after 6 weekly immunizations with a multipeptide vaccine, immunization sites were biopsied at weeks $0,1,3,7$, or 12 . In 36 participants, we enumerated DCs and lymphocyte subsets by immunohistochemistry and characterized their location within skin compartments.

Results: Mature DCs aggregated with lymphocytes around superficial vessels, however, immature DCs were randomly distributed. Over time, there was no change in mature DCs. Increases in T and B-cells were noted. Th2 cells outnumbered Th1 lymphocytes after 1 vaccine 6.6:1. Eosinophils and FoxP3 ${ }^{+}$cells accumulated, especially after 3 vaccinations, the former cell population most abundantly in deeper layers.

Conclusions: A multipeptide/IFA vaccine may induce a Th2-dominant microenvironment, which is reversed with repeat vaccination. However, repeat vaccination may increase FoxP3 ${ }^{+} T$-cells and eosinophils. These data suggest multiple opportunities to optimize vaccine regimens and potential endpoints for monitoring the effects of new adjuvants.
\end{abstract}

Trail Registration: ClinicalTrials.gov Identifier: NCT00705640

\section{Background}

Existing therapies for advanced melanoma are rarely curative. Even recent exciting data with a novel specific B-raf kinase inhibitor are limited by the transience of the clinical responses [1]. On the other hand, a large percentage of complete responses to immune therapy with interleukin-2 have been durable for over a decade [2], and other new immune therapies have been associated with long-lasting complete responses [3,4]. There is a strong rationale for the development of immune therapies specifically targeting melanoma antigens. These vaccines may be employed in the adjuvant setting,

\footnotetext{
* Correspondence: cls8h@virginia.edu

'Division of Surgical Oncology, Department of Surgery, University of Virginia, Charlottesville, VA, USA

Full list of author information is available at the end of the article
}

to treat patients who are at high risk of recurrence but are clinically free of disease. The failure of several cellbased melanoma vaccine Phase III trials has highlighted the need to optimize their efficacy [5-9]. Vaccination with purified defined antigens has the advantage of enabling the assessment of immune responses to the antigens, as well as avoiding possible toleragenic or immunosuppressive components of cell-based vaccines. Recent data from a phase III randomized trial demonstrate the clinical benefits of combining a peptide antigen vaccine with high-dose IL-2 therapy [10]. Despite its benefits, however, the majority of patients treated with this combination showed disease progression. Peripheral blood $\mathrm{T}$-cell responses to most melanoma vaccines are often transient and usually of lower magnitude than responses to viral vaccines[11]. Thus, there is evidence
C Biomed Central

() 2010 Schaefer et al; licensee BioMed Central Ltd. This is an Open Access article distributed under the terms of the Creative Commons Attribution License (http://creativecommons.org/licenses/by/2.0), which permits unrestricted use, distribution, and reproduction in any medium, provided the original work is properly cited. 
for the value of melanoma vaccines incorporating defined antigen and a need to improve their ability to induce $\mathrm{T}$ cell responses.

A variety of adjuvants, systemic cytokines, antigen formulations, doses, routes of delivery and frequency of vaccinations have been studied. Arguably, there are hundreds or thousands of permutations of these variables, only a few of which have been tested formally for their superiority over others [12-14]. If survival or systemic immune response is the study endpoint, trials testing the superiority of one approach over another may require over a hundred patients. Alternative endpoints that permit the rapid assessment of the biologic effects of adjuvants, cytokines, antigen formulation, frequencies and dose in human subjects are needed. We have found that evaluating the immune responses in the vaccinedraining node can be helpful in increasing the power of small studies to identify differences in vaccine immunogenicity, or to reinforce findings from the peripheral blood [15,16]. This approach requires substantial resources, as well as a dedicated surgeon, and is not widely applicable. On the other hand, we have found that the inflammatory infiltrate at cutaneous vaccination sites includes superficial aggregates of mature dendritic cells and lymphocytes surrounding PNAd $^{+}$vessels that resemble the high endothelial venules of lymph nodes (Harris RC et al.: Histology and immunohistology of cutaneous immune cell aggregates after injection of melanoma peptide vaccines and their adjuvant, submitted). Lymphocytes in these aggregates are actively proliferating, suggesting that they may be participating in a local immune response, challenging the classic conception that the only function of the vaccination site microenvironment is to provide antigen and dendritic cells to the draining nodes. Our experience with multipeptide vaccines in an IFA has been that we induce immune responses to one or more peptides in most patients, but many of those responses are transient $[17,18]$. Thus, we hypothesize that negative regulators of $\mathrm{Tc} 1 / \mathrm{Th} 1 \mathrm{~T}$ cell function may accumulate or be up-regulated in the vaccination site microenvironment over time. We have initiated a series of studies to explore this general hypothesis, and anticipate that this project will guide future clinical trials to optimize vaccine efficacy.

In the present study, we report observations about the inflammatory infiltrate induced by incomplete Freund's adjuvant, with or without peptide, in a clinical trial of a melanoma vaccine. We show data assessing whether: (a) 1-3 injections would induce perivascular dermal lymphoid aggregates, with accumulation of mature dendritic cells; and, (b) extended immunization (4-6 vaccines) would induce negative immune regulatory processes in the vaccination site microenvironment. This initial report focuses on direct evaluation of the cellular components and histomorphometric organization of cells in the vaccination site microenvironment. Insights gained regarding the balance of these factors over time may identify opportunities for modulation of the immunization microenvironment and for improving vaccine immunogenicity and clinical outcome.

\section{Methods}

Registration site and number: University of Virginia, NCT00705640 (ClinicalTrials.gov identifier), also referred to as the Mel48 trial

\section{Protocol}

Patients with resected AJCC stage IIB-IV melanoma arising from cutaneous, mucosal, ocular, or unknown primary sites were eligible. Inclusion criteria included: expression of HLA-A1, A2, A3, or A11 ( $85 \%$ of patients screened, data not shown); age 18 years and above; ECOG performance status 0-1; adequate liver and renal function; and ability to give informed consent. Exclusion criteria included: pregnancy; cytotoxic chemotherapy, interferon, or radiation within the preceding 4 weeks; known or suspected allergies to vaccine components; multiple brain metastases; and use of steroids or Class III-IV heart disease. Patients were studied following informed consent, as well as Institutional Review Board (IRB/HSR \#13498) and FDA approval (BB-IND \#12191).

\section{Design and sample size}

This is a companion tissue study, which is part of an open-label pilot study consisting of two treatment groups of patients with melanoma who have been immunized with a melanoma vaccine, each divided into 5 subgroups, to determine evaluation time points for a biopsy examining the injection site microenvironment. Study subjects were randomly assigned to one of ten possible arms (2 [types of replicate site injections] $\times 5$ [biopsy times] $=$ 10). In the analysis for this report, the type of injection at replicate vaccination sites was not considered.

The current report is not an assessment of the primary protocol objectives, as follow-up and analyses are not yet complete, but an assessment of the tissue specimens by 1) location within skin compartments and 2) differences over time. Initial sample size calculations were based upon a two factor design (treatment and time) which indicated that 4 subjects per cell should be adequate to determine patterns of interest. The design maintained a target of $80 \%$ power for the hypothesized effect sizes. The maximum accrual to the study was estimated to be 44 subjects in order to accrue the required 36 eligible subjects to meet the study objectives. The study was designed with an interim analysis after approximately $75 \%$ of eligible subjects for whom an evaluable biopsy was obtained. Results in the current report 
were not predefined and were noted at the time of the interim analysis. Therefore, the interim analysis significance level of 0.001 was used to guide interpretation of subsequent results.

\section{Assignment}

All patients were administered MELITAC 12.1 peptide vaccine emulsified in Montanide ISA-51VG, modified incomplete Freund's adjuvant. MELITAC 12.1 is a previously reported vaccine regimen that includes 12 melanoma associated peptides restricted by Class I MHC molecules plus a tetanus helper peptide [19]. Concurrent with the primary vaccinations, participants received a second set of injections in a replicate vaccination site. Participants were evaluated in each of two groups, one receiving MELITAC 12.1 plus IFA at the replicate vaccination site, and one receiving IFA only at the replicate vaccination site. Within each study group, participants had a surgical biopsy of the replicate site performed at one of five possible times: day 1 (no vaccine), day 8 ( 1 week after the first vaccine/week 1 ), day 22 (1 week after the third vaccine/week 3 ), day 50 (1 week after the sixth vaccine/week 6), or day 85 (6 weeks after the sixth vaccine/ 6 weeks out). These were denoted subgroups $A$, $\mathrm{B}, \mathrm{C}, \mathrm{D}$, and $\mathrm{E}$ respectively. The biopsy was an elliptical excision (width $2 \mathrm{~cm}$, length $4-6 \mathrm{~cm}$ ) of the replicate immunization site, performed under local anesthesia in the clinic.

\section{Masking}

The dermatopathologists (JTS and JWP) were unaware of the study group during the primary assessments.

\section{Participant flow}

This report is based upon data from 36 evaluable participants. Multiple biological markers were analyzed on the biopsy samples of all 36 participants.

\section{Follow-up}

Participant disease progression and survival will be closely monitored.

\section{Quantification and statistical analysis}

All data was collected at the University of Virginia Health System. For each of the 10 endpoints (CD3, CD4, CD8, CD20, Tbet, GATA3, CD1a, CD83, FoxP3 and eosinophils), and within each skin layer, the average number of counts from ten continuous high powered fields were calculated for each study subject. For each outcome, mean HPF levels were calculated for each skin layer and overall. Ratios of the means between certain outcomes of interest were calculated.

The analysis of each endpoint was performed individually using the method of generalized estimating equations (GEE) [20]. This model approach assessed relationships between cell counts (per endpoint) and two factors of interest, time of biopsy (5 levels) and layer of skin (3 levels), while assuming the absence of interaction between the factors. The response distribution was specified as negative binomial and the link function used was the natural logarithm function. Correlation between intra-subject counts obtained from different skin layers was estimated with a compound symmetric structure. Wald tests were used to determine the statistical significance of comparisons of interest, namely, differences of infiltrate counts by time point and by skin layer levels. The statistical analysis was performed using the GENMOD procedure in SAS 9.1.3 (SAS Institute, Cary, NC). All tests were performed with $\alpha=0.001$. This restrictive guideline was used in response to the issue of multiple comparisons.

Histological and immunohistochemistry methods: Paraffin-embedded tissue sections were cut and deparaffinised, and heat-based antigen retrieval was performed. A peroxidase-based enzyme system (DAB) was used according to the manufacturer's directions (Vector, Burlingame, $\mathrm{CA})$. The following primary antibodies were used: CD3 (Vector, Burlingame, CA-1:150), CD4 (Vector, Burlingame, CA-1:40), CD8 (DakoCytomation, Denmark-1:50), CD20 (Dako, Denmark-1:200), Tbet (Santa Cruz, CA -1:20), GATA3 (BD Pharmingen, San Jose, CA-1:100), FoxP3 (clone PCH101, eBioscience, San Diego, CA-1:125), CD1a (Dako, Denmark-1:50), CD83 (Leica, Wetzlar, Germany-1:20). Specificity was demonstrated by the absence of staining products using nonimmune corresponding immunoglobulin. Human lymph nodes were used as positive controls. Quantification of superficial dermal, deep dermal and subcutaneous endpoints was performed by capturing images of hematoxylin/eosin and immunohistochemical sections using an Olympus BX51 microscope and Olympus DP71 camera (Olympus, Center Valley, PA)

\section{Results}

\section{Eligibility review}

This report summarizes histologic data from 36 evaluable patients enrolled between June 5, 2008 and May 5, 2009 on the Mel48 clinical trial (Figure 1). Overall, 72\% were male, and median age was 53 years. Median ages across study time points were $(57,60,52,43$, and 55 for groups A through E, respectively). All patients were Caucasian, none were Hispanic.

\section{Histomorphology: The histomorphologic spectrum demonstrates evolution of a transient, prominent lymphohistiocytic infiltrate}

Histomorphometric analysis of the immunization site microenvironment (ISME) was first performed by 


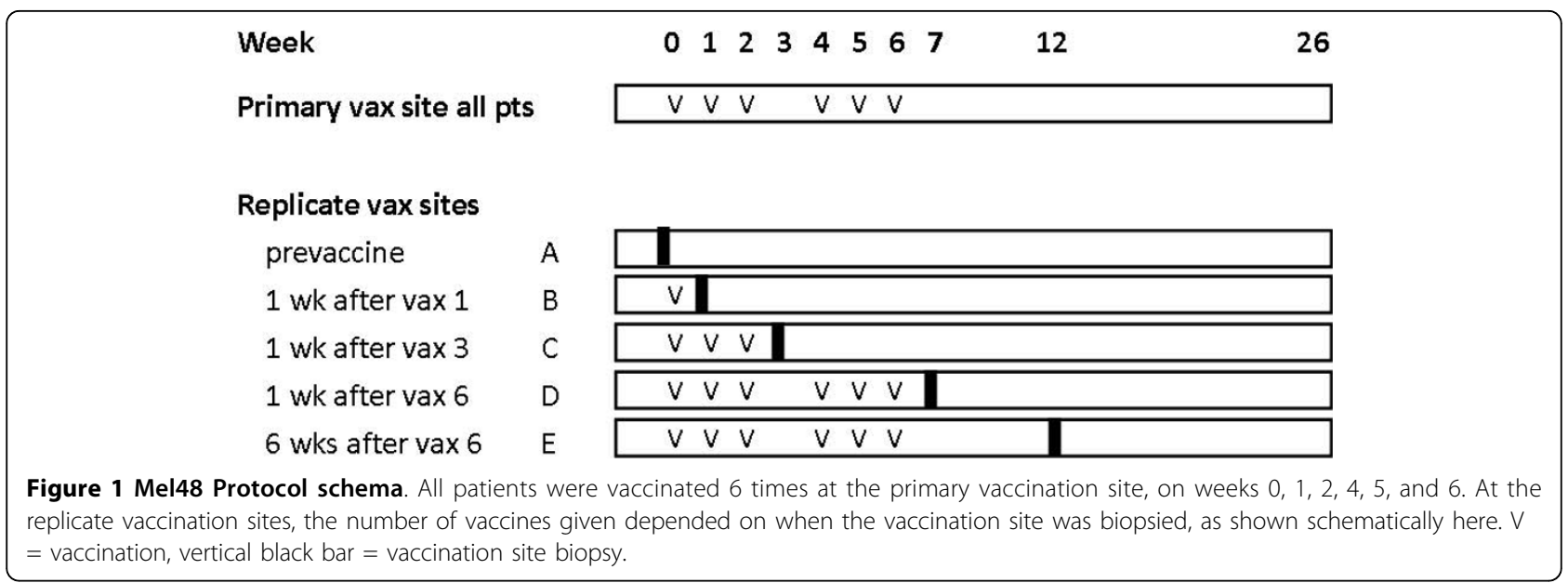

microscopic evaluation of histologic sections of skin at the vaccine sites, collected at one of 5 time points from each of the 36 patients biopsied in this study population. Representative images of the superficial and deep dermis and subcutis are shown in Figure 2. Prior to the first vaccine (time point A, Figure 2), few lymphocytes were evident in the superficial dermis, surrounding the superficial vascular plexus, which represents normal skin. After the first vaccine, however, increased numbers of inflammatory cells were evident, not only around the superficial vessels, but also around the deep dermal vasculature and eccrine coils. The inflammatory infiltrate increased and filled nearly the entire dermis and subcutis following the third and sixth vaccines. Six weeks past the last vaccine (time point E, Figure 2), the cellular infiltrate receded from the dermis and subcutis and mainly surrounded superficial and deep dermal blood vessels and adnexal structures.

After three vaccines, foreign-body type giant cells were observed. In the subcutis, the infiltrates assumed a

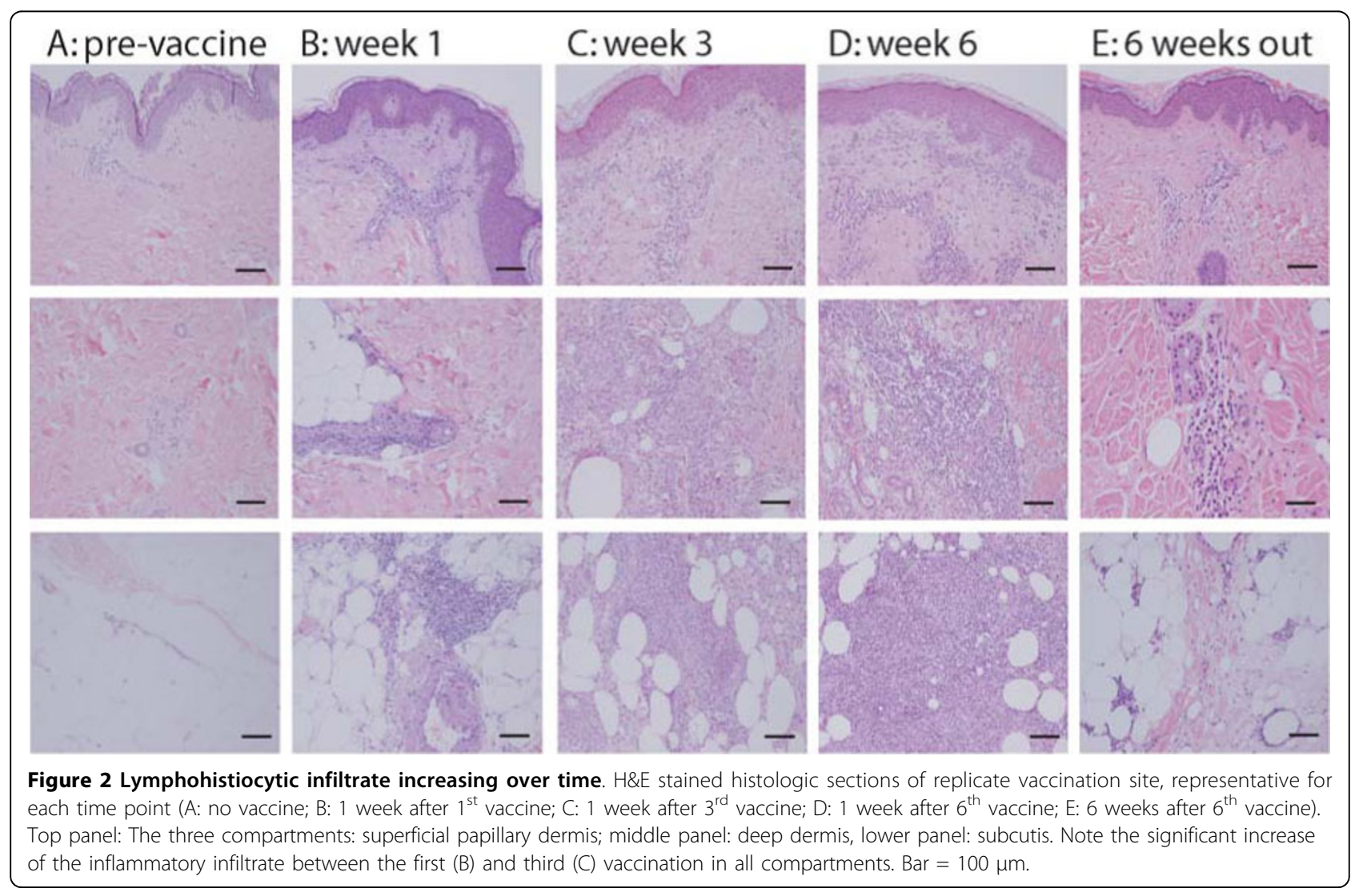


configuration reminiscent of combined septal and lobular panniculitis. Striking tissue eosinophilia was noted in the deep layer of two-thirds of cases, while at least moderate numbers of eosinophils were observed in all cases at time point $\mathrm{C}$ or later (Figure $3 \mathrm{~A}$ and $3 \mathrm{~B}$ ). Areas of fat necrosis were also observed (Figure $3 C$ ). Large, spherical "empty spaces", demarcated by a prominent granulomatous reaction, were evident in the subcutis. These spaces represent adjuvant deposits, which were dissolved during tissue processing (Figure 3D).

Similar histomorphologic and immunophenotypic findings were observed in arms 1 and 2 (IFA without or with peptide antigens, respectively, data not shown).

\section{Characterization of the lymphocytes infiltrating the ISME}

To further characterize the cellular components of the infiltrate, a series of immunohistochemical (IHC) studies were performed. The lymphocytic infiltrates had a dominant T-cell $\left(\mathrm{CD}^{+}\right)$component, with a smaller $\mathrm{CD} 20^{+}$ $\mathrm{B}$-cell component (Figure 4). $\mathrm{CD}^{+} \mathrm{T}$ cells were more dispersed, whereas $\mathrm{CD}^{+}{ }^{+} \mathrm{T}$ cells were frequently encountered in clusters, especially around blood vessels (perivascular T-cell zone - CD4 population not shown). $\mathrm{CD} 20^{+} \mathrm{B}$-cells occured singly or in clusters and were sometimes intimately associated with the perivascular T-cell zones.
The number of $\mathrm{T}$ cells $\left(\mathrm{CD}^{+}\right)$increased from a mean of 5.3 per high-power field (HPF) prevaccine to 17.6 at time point B, with a further increase to 81.9 at week 3 (C), which represented a statistically significant increase ( $\mathrm{p}<0.001$ - all statistically significant findings reported in this study have a p-value below 0.001 , Figures 5 and 6 - figure 5 shows data of all 36 patient while figure 6 only represents data of patients receiving both adjuvant and peptide at the replicate vaccine site). The numbers appeared stable through week 7 without any statistical changes thereafter. The $\mathrm{CD} 4^{+}$and $\mathrm{CD} 8^{+} \mathrm{T}$ cell subsets showed a statistical significant increase over the same time course from time point $\mathrm{A}$ to $\mathrm{B}$ and to $\mathrm{C}$, with a plateau through time point $\mathrm{E}$ (Table 1). Mean numbers of $\mathrm{CD}^{+}{ }^{+} \mathrm{T}$ cells per hpf at those 5 time points were 3.8 , 14.3, 57.8, 82.5 and 64.6, respectively, and for $\mathrm{CD}^{+} \mathrm{T}$ cells were $2.8,9.9,41.2,53.4$ and 51.6. For $\mathrm{CD}^{+}$and $\mathrm{T}$-cell subsets $\mathrm{CD} 4^{+}$and $\mathrm{CD} 8^{+}$, there were no consistent differences between skin compartments (superficial, papillary dermis, reticular dermis and subcutis) across time points. B-cell numbers showed a trend towards increasing slightly after one vaccine, but then increased significantly by week 3 and 7 ( $\mathrm{p}<0.001$, Figures 5 and 6 ).

\section{T-helper subpopulations}

A goal of peptide vaccines is to induce cytotoxic T cells, which depend on Th1 help. Thus, we evaluated the Th1/
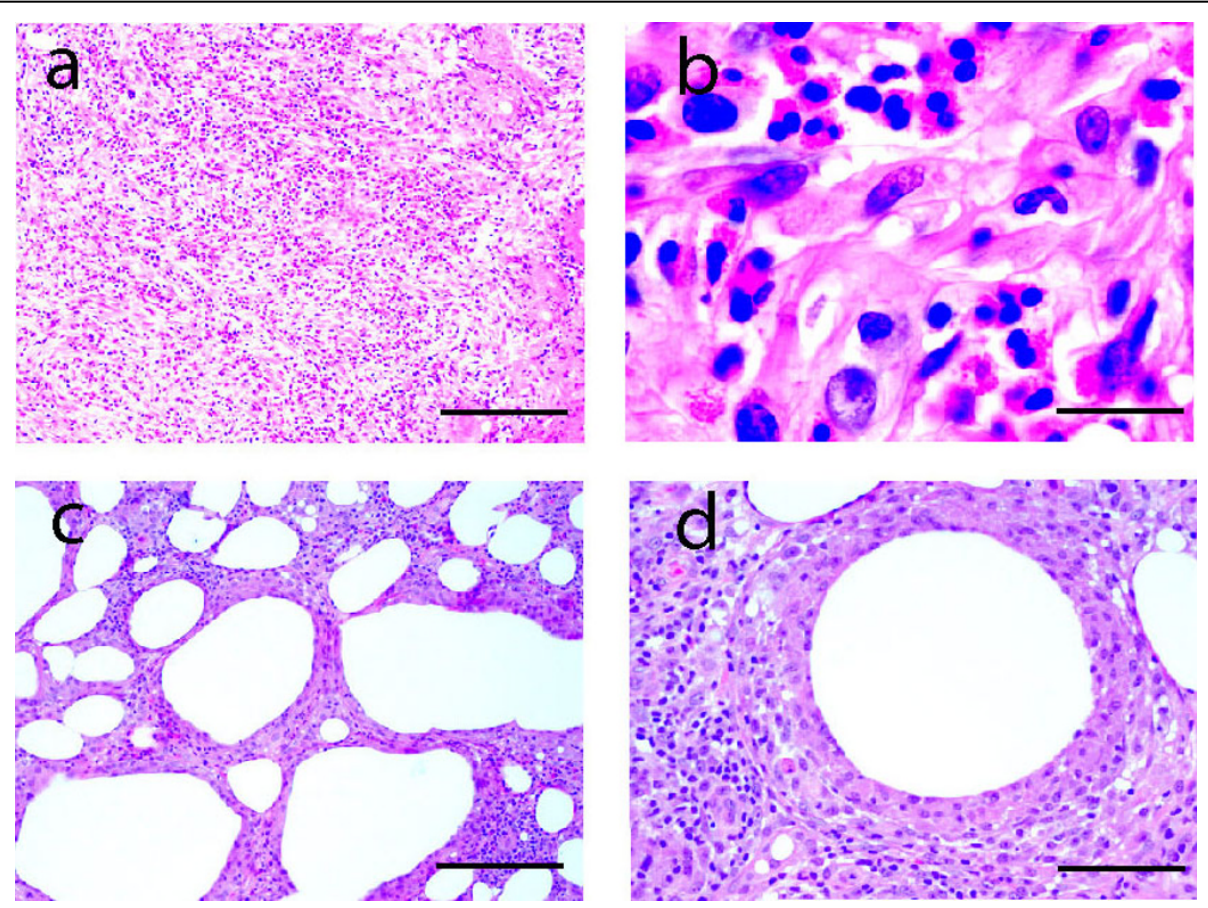

Figure 3 Pools of eosinophilis in the mid and deep layers following the third vaccine. (a) Numerous eosinophils are present in the subcutis. Bar $=200 \mu \mathrm{m}$. (b) High-power view. Note the distinctive cytologic detail, including the bilobed nucleus in a round cell with numerous, red cytoplasmic granules. Bar $=20 \mu \mathrm{m}$ (c) Focal areas of fat necrosis (empty spaces of various sizes) are present. Bar $=200 \mu \mathrm{m}$ (d) Note sites of vaccine deposits (large, "empty" spaces walled off by macrophages. Bar $=100 \mu \mathrm{m}$. 

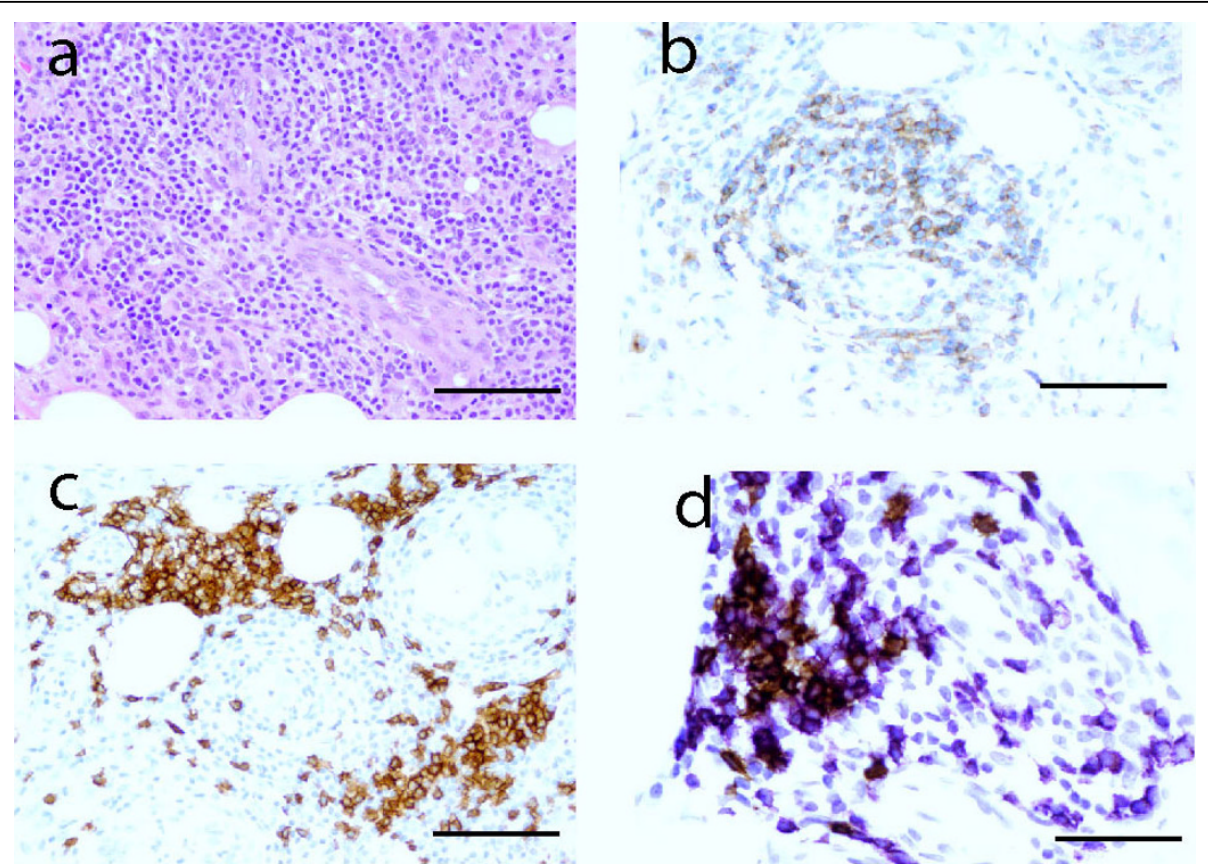

Figure 4 Perivascular T-and B-cell infiltrate. (a) Prominent infiltrate of inflammatory cells composed of lymphocytes and macrophages. (b) $\mathrm{CD}^{+}$T-cells (brown chromagen) cluster around blood vessel. (c) CD20 B-cells (brown chromagen) group peripheral to the T-cell zone. Bar $=$ $100 \mu \mathrm{m}$ in a-c. (d) Double-staining for $\mathrm{CD}_{2}{ }^{+}$B-cells (brown membranous stain) and CD8 (purple membranous stain). Counter-staining with hematoxylin marks nuclei blue. Note the group of B-cells located distant from blood vessel and next to the perivascular zone. The latter is composed of purple T-cells (we show the $\mathrm{CD}^{+}$population here) Bar $=50 \mu \mathrm{m}$.

Th2 bias of the $\mathrm{CD} 4^{+} \mathrm{T}$ cells in the ISME by staining for T-bet (Th1) and GATA-3 (Th2). The T-bet ${ }^{+}$cells were very rare pre-vaccine and did not change after 1 vaccine, but increased significantly by week 3 ( $\mathrm{p}<0.001$; C vs B; Figures 7 and 8 - figure 7 shows data of all 36 patient while figure 8 only represents data of patients receiving both adjuvant and peptide at the replicate vaccine site). In contrast, $\mathrm{GATA}^{+}$cells increased significantly over time through weeks 1 and 3 (Figures 7 and 8). At week 1 and week 3 , the GATA- $3^{+} /$T-bet $^{+}$ratios were approximately $6.6: 1$ and $1: 1$, respectively (Table 2 ). There were statistically significant layer effects for GATA3 showing increased numbers in the deep layer that seem to have been driven by later time points.

\section{Eosinophils}

Tissue eosinophilia was evaluated on H\&E stained-sections. Eosinophils were absent or very rare pre-vaccine (Figures 7 and 8) with no obvious change after the first vaccine. However, there was a statistically significant increase after three vaccines (Figures 7 and 8 ). There was also a layer effect with the superficial compartment showing significantly less eosinophils than the mid and deep compartments.

\section{FOXP3 $^{+}$cell population}

FoxP $^{+}$cells were also enumerated: no obvious change was noted after the first vaccination, but there was a statistically significant increase after 3 vaccines (Figures 7 and 8). No overall differences were noted when the superficial, mid and deep layers were compared.

\section{Immature and mature dendritic cells}

For mature $\left(\mathrm{CD} 3^{+}\right)$DCs, there was a significant decrease from the superficial to both the mid and deep compartment. Mature $\left(\mathrm{CD} 83^{+}\right) \mathrm{DC}$ were primarily found in the superficial dermis (Figures 5 and 6) and were clustered around superficial papillary dermal blood vessels and adnexal structures. $\mathrm{CD} 1 \mathrm{a}^{+}$immature dendritic cells were randomly distributed within the inflammatory infiltrates; slightly increased numbers were seen in the superficial compartment. No obvious changes were noted in mature DCs over time (Figure 5 and 6). Although statistically significant, the increase of immature $\left(\mathrm{CD} \mathrm{a}^{+}\right) \mathrm{DCs}$ over time was small.

\section{Discussion}

Prior studies have examined the histopathology of delayed-type hypersensitivity (DTH) reactions, specifically following dendritic cell vaccines (Table 3). DTH reactions are dominated by perivascular $\mathrm{T}$-cell infiltrates [21-24]. Time-course assessments have been lacking, as they have only been reported for one patient in a small study [25]. Prior studies did not examine primary vaccination sites, and did not address the impact of adjuvants 

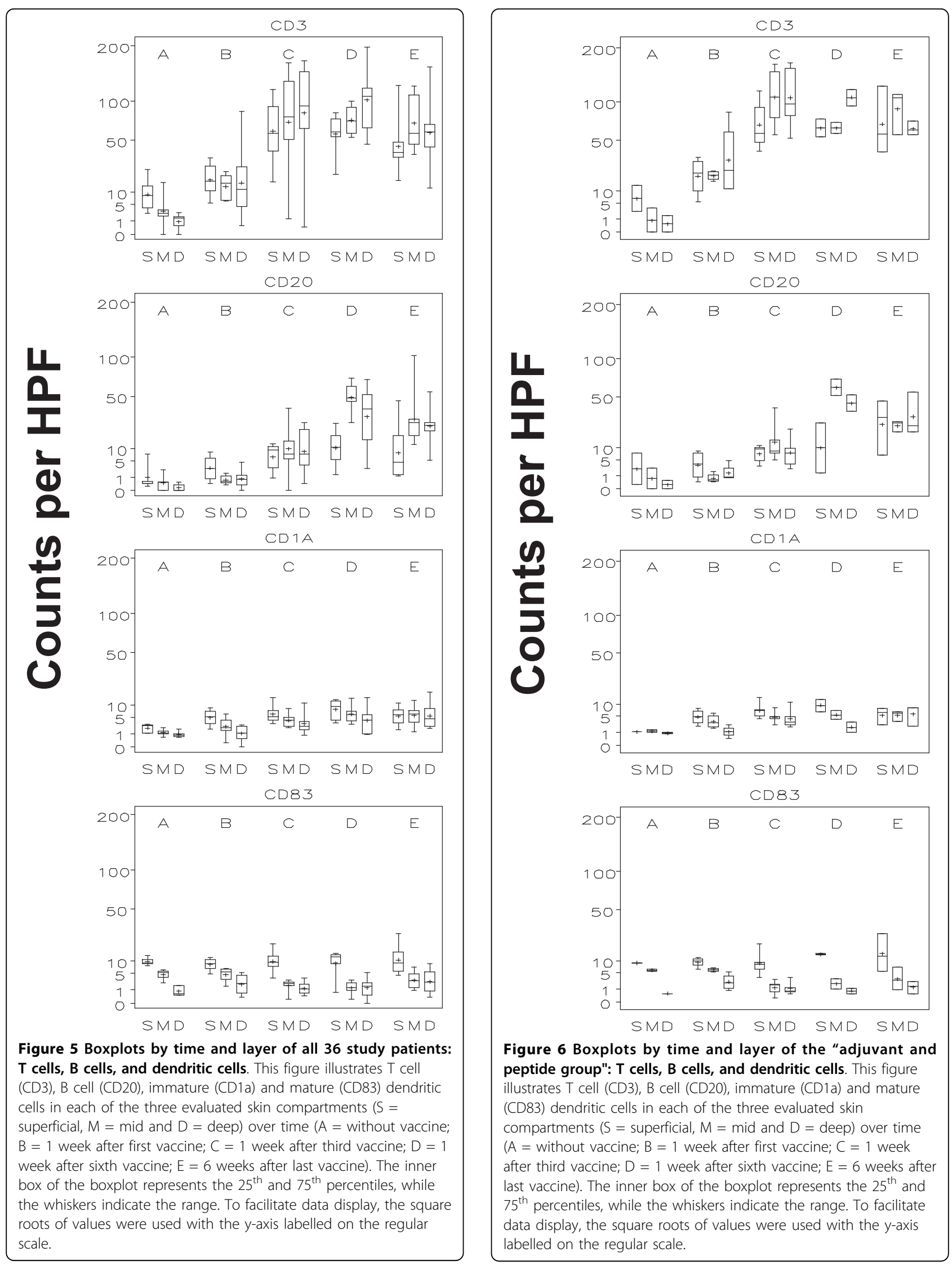
Table $1 \mathrm{CD}^{+}$and $\mathrm{CD}^{+}{ }^{+} \mathrm{T}$ cells in ISME

\begin{tabular}{lccc}
\hline TIME POINT & \multicolumn{2}{c}{ NUMBER OF CELLS PER HPF } & CD4 $^{+}$:CD8 $^{+}$RATIO \\
\cline { 2 - 3 } & CD4 $^{+}$ & CD8 $^{+}$ & \\
\hline A (pre-vaccine) & 3.8 & 2.8 & 1.3 \\
\hline B (week 1) & 14.3 & 9.9 & 1.4 \\
\hline C (week 3) & 57.8 & 41.2 & 1.4 \\
\hline D (week 7) & 82.5 & 53.4 & 1.5 \\
\hline E (6 weeks out) & 64.6 & 51.6 & 1.3 \\
\hline
\end{tabular}

on recruiting immune cells for the induction of immune responses. To our knowledge, a systematic histologic and immunophenotypic characterization of vaccination site microenvironments has not been previously performed.

In the present study, we describe the character, magnitude and time-course of the inflammatory infiltrate at the vaccination site in patients receiving a multipeptide vaccine in an incomplete Freund's adjuvant, with quantitative evaluation of superficial and deep dermis including the subcutis. The cellular infiltrate consisted mainly of T-lymphocytes and evolved to maximum intensity after the third vaccination. Over a similar time frame, cells accumulated that may have negative effects on induction of $\mathrm{Th} 1 / \mathrm{Tc} 1$ responses at the vaccination site. These included evidence of an early Th2 dominant microenvironment, with subsequent accumulation of eosinophils and FoxP3 ${ }^{+}$T-cells. For all of these populations, we observed significant increases and subsequent plateau after the third vaccination (time point $\mathrm{C}$ ).

DCs are crucial for the initiation, regulation and programming of antigen-specific responses [26,27]. Thus, we also investigated their presence and location in the vaccination site microenvironment. We found that mature DCs clustered around the superficial vascular plexus and periadnexal structures in association with lymphocyte aggregates, suggesting their possible role in priming $\mathrm{T}$ cells in this microenvironment. The deep infiltrate contained very few mature DCs despite overall high cellularity. Mature DCs maintained their physiologic distribution and did not significantly increase over the time course of the vaccination protocol. Possible explanations for the stagnant number of mature DCs include immune regulation in the vaccination site microenvironment or migration of mature DCs to draining lymph nodes. Although small, a statistically significant increase of immature DCs was noted with multiple vaccinations, reflecting a stimulatory effect on antigenpresenting cells. Factors that enhance dendritic cell maturation might be necessary and may have been missing. The combination of toll-like receptor agonists (TLRs), anti-CD40, IFN- $\gamma$ and surfactant can augment DC activation and subsequent cytotoxic T lymphocyte

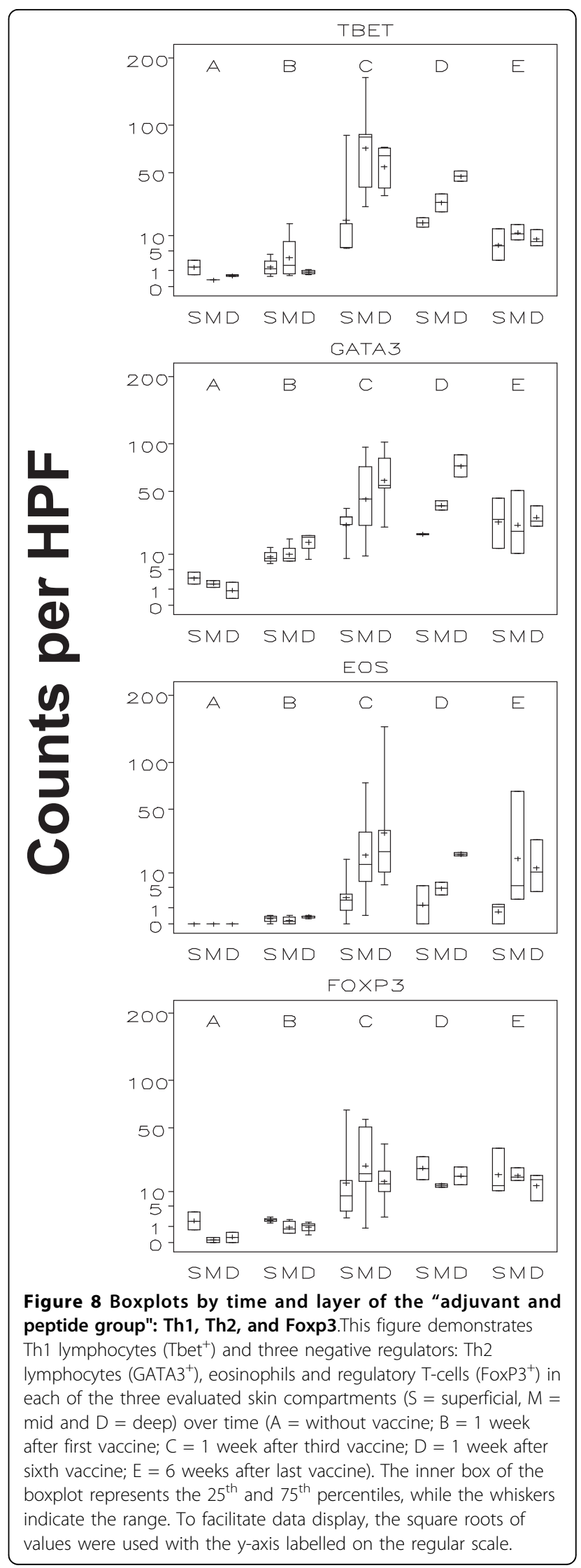




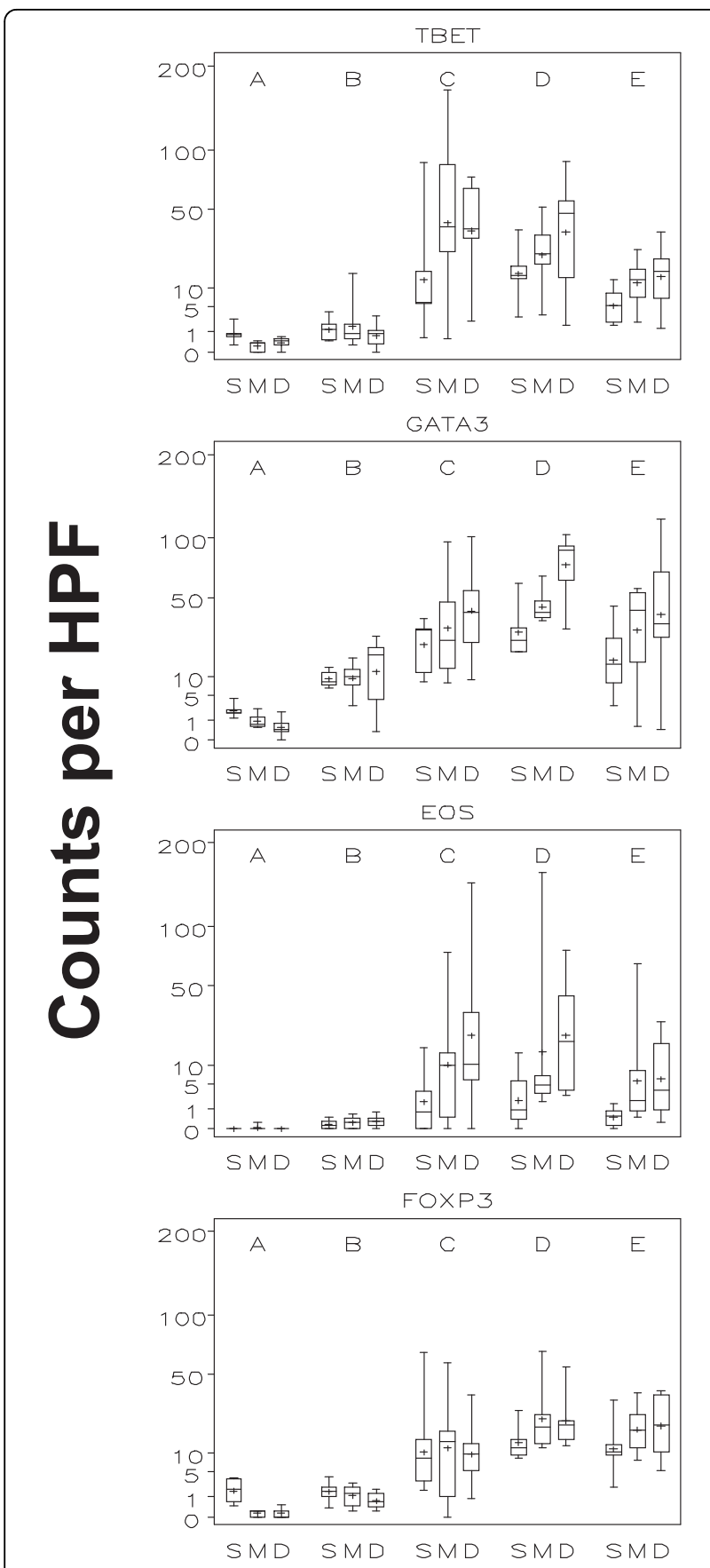

Figure 7 Boxplots by time and layer of all 36 study patients: Th1, Th2, and Foxp3 (Figure 7 demonstrates all 36 study patients. Figure 8 only shows the "adjuvant and peptide group"). This figure demonstrates Th1 lymphocytes (Tbet ${ }^{+}$) and three negative regulators: Th2 lymphocytes $\left(\right.$ GATA $\left.^{+}\right)$, eosinophils and regulatory T-cells (FoxP3 ${ }^{+}$) in each of the three evaluated skin compartments ( $S=$ superficial, $M=$ mid and $D=$ deep) over time ( $A=$ without vaccine; $B=1$ week after first vaccine; $C=1$ week after third vaccine; $D=1$ week after sixth vaccine; $E=6$ weeks after last vaccine). The inner box of the boxplot represents the $25^{\text {th }}$ and $75^{\text {th }}$ percentiles, while the whiskers indicate the range. To facilitate data display, the square roots of values were used with the $y$-axis labelled on the regular scale.
Table 2 GATA3 and T-bet ${ }^{+} T$ cells in ISME

\begin{tabular}{lccc}
\hline TIME POINT & \multicolumn{2}{l}{ NUMBER OF CELLS PER HPF } & GATA3:T-BET RATIO \\
\cline { 2 - 3 } & $\begin{array}{c}\text { GATA3 } \\
\text { (Th2) }\end{array}$ & $\begin{array}{l}\text { T-bet } \\
\text { (Th1) }\end{array}$ & \\
\hline A (pre-vaccine) & 1.3 & 0.5 & 2.8 \\
\hline B (week 1) & 11.1 & 1.7 & 6.6 \\
\hline C (week 3) & 35.4 & 37.9 & 0.9 \\
\hline D (week 7) & 50.6 & 28.2 & 1.8 \\
\hline E (6 weeks out) & 33.4 & 11.4 & 2.9 \\
\hline
\end{tabular}

formation. Activation of DCs may be drastically improved if two or more of these factors are added [28].

The present vaccination approach was designed to induce cytotoxic $\mathrm{T}$ cells reactive to Class I MHC-associated melanoma peptides, which classically depend on support from Th1 helper T cells. In contrast, Th2 cells support humoral immunity. The transcription factor Tbet controls development of Th1, while GATA-3 directs the Th2 lineage [29]. Therefore, our goal was to optimize Th1-dominant responses to the vaccine, and a tetanus helper peptide was included to expand Th1 helper $\mathrm{T}$ cells. In prior trials, this tetanus peptide did induce Th1-dominant responses [30], and combinations with Class I MHC associated peptides induced antigenspecific cytotoxic $\mathrm{T}$ cells $[15,18]$. Thus, it was surprising to find a significant increase of Th2 cells following the first vaccine, leading to Th2 dominance (Table 2). This finding likely has relevance for others using IFA adjuvants, as it reflects an unbalanced early Th2 dominance with the potential to compromise induction of Th1 and Tc1 responses.

The current study also tested the effects of additional vaccinations at the same location. Th1 cells culminated after the $3^{\text {rd }}$ vaccination and outnumbered Th2 helper $\mathrm{T}$-cells. One hypothesis is that Th1 cells rapidly emigrate from the vaccination site to populate the periphery. However, we have rarely observed detectable $\mathrm{T}$ cell responses in PBMC at just one week, and usually do not observe them until at least $2-3$ weeks $[17,18]$. Therefore, we suggest that a minimum of three vaccines at the same site are needed to trigger sufficient numbers of Th1 helper lymphocytes with this vaccine and adjuvant combination. Alternatively, the addition of TLR agonists or other immune modulators may be explored as means to induce an earlier Th1 dominant vaccination site microenvironment.

In a Th2-rich infiltrate, a dominant cytokine produced is IL-5, which is chemotactic for eosinophils [29]. Therefore, the marked tissue eosinophilia observed after several weeks is likely to be a longer-term manifestation of the Th2 dominant early response and the persistence of Th2 cells through week 12 . We found a significant compartmental accentuation of eosinophils and Th2 cells, 
Table 3 Histopathology of delayed-type hypersensitivity (DTH) reactions, specifically following dendritic cell vaccines*

\begin{tabular}{|c|c|c|c|c|c|}
\hline Literature source & $\mathrm{CD4}^{+} \mathrm{T}$ cells & $\mathrm{CD8}^{+} \mathrm{T}$ cells & $\mathrm{CD}^{2} 0^{+} \mathrm{B}$ cells & CD56 $^{+}$NK cells & Distribution \\
\hline Nestle, et al. (1998) [21] & $\mathrm{CD}^{2} 5 \mathrm{RO}^{+} \& \mathrm{CD}^{+}$ & NM & NM & NM & perivascular \\
\hline Bedrosian, et al. (2003) [24] & Few & numerous & NM & NM & perivascular \\
\hline de Vries, et al. (2005) [23] & $50-70 \%$ & $30-50 \%$ & None & NM & perivascular \\
\hline Nakai, et al. (2006) [22] & Majority & $<\mathrm{CD}^{+}$ & NM & NM & perivascular \\
\hline Nakai (2009) [25] & $\geq \mathrm{CD}+^{+}$ & $\leq \mathrm{CD}^{+}$ & NM & None & Perivascular \\
\hline
\end{tabular}

$\mathrm{NM}=$ not mentioned

*Where reported, all were evaluated based on punch biopsies. The biopsy method was not described by Nestle (1998) and Nikai (2006).

primarily in the deep dermis and subcutaneous tissue. In the superficial dermis, however, both Th2 lymphocytes and eosinophils were less common, suggesting the presence of biologically relevant subset microenvironments within the overall vaccination site. Given the observed layer effect among compartments, the superficial papillary dermis may have less of a Th2 effect, suggestive of the possibility that this compartment may be a more receptive environment for inducing a Th1/Tc1 response.

Regulatory $\mathrm{T}$ cells represent another mechanism by which the immune response to vaccines may be limited. FoxP ${ }^{+}$cells, identified by nuclear immunohistochemical staining, corresponded well with the $\mathrm{CD} 4^{+} \mathrm{CD} 25^{\text {high }}$ FoxP ${ }^{+}$regulatory $\mathrm{T}$ cell populations identified by flow cytometry using multi-antibody labeling [31]. FoxP3 expression can be found in activated non-regulatory $\mathrm{T}$ cells [32-35]. However, high numbers of FoxP3 ${ }^{+}$cells detected by immunohistochemistry in inflamed skin and cancer tissue most likely represent regulatory $\mathrm{T}$ cells $[36,37]$. In the present study, FoxP3 ${ }^{+}$cells increased following the third vaccination and persisted through week 12. The third vaccination again represents a critical time point in the induction of negative regulators.

With respect to $\mathrm{T}$ lymphocyte subsets (CD4, CD8) and B-cells (CD20), all populations increased significantly, especially following the third vaccination. CD4: CD8 ratios of 1:1 to 3:1 have been described in DTH reaction sites following a recall injection $[21,23,25]$ and in classical DTH reactions [38]. Our ratios were at the lower end of that range and lower than the physiologic 2:1 ratio in lymph nodes, with time point specific CD4: CD8 ratios between 1.3:1 and 1.5:1 (Table 2). CD20 ${ }^{+}$Bcell clusters were observed in juxtaposition to a $\mathrm{CD}^{+}$ $\mathrm{T}$-cell zone immediately surrounding the vascular lumens (Figure 4). This zonation was reminiscent of white pulp seen in the spleen. Overall, parallels between the perivascular infiltrates and normal architecture of lymph nodes and spleen are compelling. However, we have not observed germinal center formation within the B-cell clusters. Thus, not all features of tertiary lymphoid organs were present, as have been described in certain chronic inflammatory disorders [39].
The early induction of Th2 cells in the vaccine microenvironment suggests that adjuvants that could increase Th1 cytokines may be valuable. In particular, IL-12 and adjuvants that induce IL-12 production may be advantageous immune modulators by enhancing Th1 polarization. Alternatively, interleukin-5 antibodies such as mepalizumab might be useful if repeat vaccinations are being performed at the same site and compartment, by controlling tissue eosinophilia and directly interfering with Th2 cytokine activity. This maneuver could potentially reverse the IL-5 dominant milieu and tip the balance to a Th1-dominant environment.

Finally, these data suggest guidance regarding where and how vaccinations should be performed. Changing to a new vaccination site following the third injection (or sooner) may minimize potential adverse effects observed by repeat antigen injection into a microenvironment populated with high numbers of regulatory $\mathrm{T}$ cells. However, such change also has the potential limitation of placing the antigenic peptide in an immunologically "unprimed" environment. Short peptides have a brief halflife in the presence of natural peptidases $[11,40]$. Thus, peptide presentation in close proximity to mature DC's may be important. The use of longer peptides has been suggested [41-43], as they may prolong antigen persistence in the vaccine microenvironment and ensure presentation only by professional antigen-presenting cells. The ideal vaccine protocol will maximize the contact time between peptides and competent antigen presenting cells by using an optimal peptide/adjuvant combination.

Many cancer vaccines are administered subcutaneously, even though intradermal antigen presentation is an alternative. In this study, we focused on all compartments of the vaccination site, and found more mature DCs present in the superficial papillary dermis than in either the deep dermis or subcutis (mid and deep compartments). Dense eosinophil populations accumulated in the deeper layers relative to the superficial compartment. Thus, these data also suggest that intradermal or even transdermal vaccines may be optimal. Transdermal delivery models have been found to be safe and effective for prophylactic vaccines [44-46]. 
Recent studies exploring the advantages of nanoparticulate antigen systems in humans offer an interesting alternative to intramuscular, dermal and subcutaneous vaccination [47]. Using this approach, immunogenicity could be induced using only one fifth of the antigen dose required for intramuscular vaccination [48].

The histomorphologic and immunophenotypic observations regarding cellular infiltrates in the vaccine microenvironment do not seem to be antigen-dependent, since the observations for both the adjuvant + peptide group (Figures 5 and 7) and the adjuvant only group (Figures 6 and 8) were similar. However, a comprehensive analysis of the antigen-specific immune response at the vaccination site and in the peripheral blood is currently underway.

\section{Conclusions}

Despite the induction of $\mathrm{CD}^{+}$and $\mathrm{CD} 8^{+} \mathrm{T}$-cell responses in most patients when peptide vaccines are administered in incomplete Freund's adjuvant $[19,49,50]$, the immunization site microenvironment may not be optimized for induction of Th1/Tc1 responses. This is the first study of its kind that examines the immunization site microenvironment. The relevance of its findings will need to be tested, by correlation with systemic immune response and clinical outcome, in future randomized studies using different adjuvant systems and/or immunogens. As part of the ongoing clinical trial that provided the tissue samples for this study, circulating immune responses to the vaccines will be measured and reported when available, with the possibility that some critical correlations may be elucidated.

\begin{abstract}
Acknowledgements
This study was funded by NIH/NCI grant R01CA57653 (to C.L.S). (Principal investigator: Craig L. Slingluff, Jr.) Support was also provided by the University of Virginia Cancer Center Support Grant (NIH/NCI P30 CA44579, Biorepository and Tissue Research Facility) and the University of Virginia General Clinical Research Center (NIH M01 RR00847). Peptides used in this vaccine were prepared with philanthropic support from the Commonwealth Foundation for Cancer Research and Alice and Bill Goodwin. Additional philanthropic support was provided from the James and Rebecca Craig Foundation, George S. Suddock, Richard and Sherry Sharp, and the Patients and Friends Research Fund of the University of Virginia Cancer Center. Montanide ISA-51 (produced by Seppic, Inc.) was used in the vaccines of this trial, but paid for by the University of Virginia. No corporate funding support was provided for this study.
\end{abstract}

\section{Author details \\ 'Division of Surgical Oncology, Department of Surgery, University of Virginia, Charlottesville, VA, USA. ${ }^{2}$ Human Immune Therapy Center, University of Virginia, Charlottesville, VA, USA. ${ }^{3}$ Department of Pathology, University of Virginia, Charlottesville, VA, USA. ${ }^{4}$ Department of Dermatology, University of Virginia, Charlottesville, VA, USA. ${ }^{5}$ Department of Public Health Sciences, University of Virginia, Charlottesville, VA, USA}

\section{Authors' contributions}

JTS carried out histological sections and immunohistochemical preparations, data collection, data analysis and preparation of the manuscript. JWP independently performed data collection and analysis and critically reviewed and revised the manuscript. DHD optimized the immunohistochemical methods. GRP and MES were equally involved in the program development of this trial and performed the statistical tests and played an important role in the data analysis. MEJ carried out patient recruitment, randomization and logistics of the data collection. CLS was the principal investigator and participated in the data collection and analysis and preparation of the manuscript. All authors have read and approved the final manuscript of this paper.

\section{Competing interests}

CLS is an inventor on several patents for peptides used in melanoma vaccines, these patents are held through the University of Virginia Patent Foundation. CLS is also on a scientific advisory board for Immatics Biotechnologies $\mathrm{GmbH}$, which tests peptide vaccines. The other authors state no conflict of interest.

Received: 7 April 2010 Accepted: 20 August 2010

Published: 20 August 2010

\section{References}

1. Puzanov I, Nathanson KL, Chapman PB, Xu X, Sosman JA, McArthur GA, Ribas A, Kim KB, Grippo JF, Flaherty KT: PLX4032, a highly selective V600EBRAF kinase inhibitor: Clinical correlation of activity with pharmacokinetic and pharmacodynamic parameters in a phase I trial. J Clin Oncol (Meeting Abstracts) 2009, 27:9021.

2. Rosenberg SA, Yang JC, White DE, Steinberg SM: Durability of complete responses in patients with metastatic cancer treated with high-dose interleukin-2: identification of the antigens mediating response. Ann Surg 1998, 228:307-319.

3. Powell DJ Jr, Dudley ME, Hogan KA, Wunderlich JR, Rosenberg SA: Adoptive transfer of vaccine-induced peripheral blood mononuclear cells to patients with metastatic melanoma following lymphodepletion. J Immunol 2006, 177:6527-6539.

4. Hunder NN, Wallen H, Cao J, Hendricks DW, Reilly JZ, Rodmyre R, Jungbluth A, Gnjatic S, Thompson JA, Yee C: Treatment of metastatic melanoma with autologous CD4+ T cells against NY-ESO-1. N Engl J Med 2008, 358:2698-2703.

5. Wallack MK, Sivanandham M, Balch CM, Urist MM, Bland KI, Murray D, Robinson WA, Flaherty L, Richards JM, Bartolucci AA, Rosen L: Surgical adjuvant active specific immunotherapy for patients with stage III melanoma: the final analysis of data from a phase III, randomized, double-blind, multicenter vaccinia melanoma oncolysate trial. J Am Coll Surg 1998, 187:69-77, discussion 77-69.

6. Sondak VK, Liu PY, Tuthill RJ, Kempf RA, Unger JM, Sosman JA, Thompson JA, Weiss GR, Redman BG, Jakowatz JG, et al: Adjuvant immunotherapy of resected, intermediate-thickness, node-negative melanoma with an allogeneic tumor vaccine: overall results of a randomized trial of the Southwest Oncology Group. J Clin Oncol 2002, 20:2058-2066.

7. Kirkwood JM, Ibrahim JG, Sosman JA, Sondak VK, Agarwala SS, Ernstoff MS Rao U: High-dose interferon alfa- $2 b$ significantly prolongs relapse-free and overall survival compared with the GM2-KLH/QS-21 vaccine in patients with resected stage IIB-III melanoma: results of intergroup trial E1694/S9512/C509801. J Clin Oncol 2001, 19:2370-2380.

8. Schadendorf D, Nestle FO, Broecker EB, Enk A, Grabbe S, Ugurel S, Edler L, Schuler G: Dacarbacine (DTIC) versus vaccination with autologous peptide-pulsed dendritic cells (DC) as first-line treatment of patients with metastatic melanoma: Results of a prospective-randomized phase III study. J Clin Oncol (Meeting Abstracts) 2004, 22:7508.

9. Morton DL, Mozzillo N, Thompson JF, Kelley MC, Faries M, Wagner J, Schneebaum S, Schuchter L, Gammon G, Elashoff R, Group MCT: An international, randomized, phase III trial of bacillus Calmette-Guerin (BCG) plus allogeneic melanoma vaccine (MCV) or placebo after complete resection of melanoma metastatic to regional or distant sites. J Clin Oncol (Meeting Abstracts) 2007, 25:8508.

10. Schwartzentruber DJ, Lawson D, Richards J, Conry RM, Miller D, Triesman J, Gailani F, Riley LB, Vena D, Hwu P: A phase III multi-institutional randomized study of immunization with the gp100: 209-217(210M) peptide followed by high-dose IL-2 compared with high-dose IL-2 alone in patients with metastatic melanoma. $J$ Clin Oncol (Meeting Abstracts) 2009, 27:CRA9011. 
11. Brinckerhoff LH, Kalashnikov W, Thompson LW, Yamshchikov GV, Pierce RA, Galavotti HS, Engelhard VH, Slingluff CL Jr: Terminal modifications inhibit proteolytic degradation of an immunogenic MART-1(27-35) peptide: implications for peptide vaccines. Int J Cancer 1999, 83:326-334.

12. Davis ID, Chen W, Jackson H, Parente P, Shackleton M, Hopkins W, Chen Q, Dimopoulos N, Luke T, Murphy R, et al: Recombinant NY-ESO-1 protein with ISCOMATRIX adjuvant induces broad integrated antibody and CD4 (+) and CD8(+) T cell responses in humans. Proc Natl Acad Sci USA 2004, 101:10697-10702.

13. Celis E: Overlapping human leukocyte antigen class $\mathrm{I} / \mathrm{I}$ binding peptide vaccine for the treatment of patients with stage IV melanoma: evidence of systemic immune dysfunction. Cancer 2007, 110:203-214.

14. Spaner DE, Astsaturov I, Vogel T, Petrella T, Elias I, Burdett-Radoux S, Verma S, Iscoe N, Hamilton P, Berinstein NL: Enhanced viral and tumor immunity with intranodal injection of canary pox viruses expressing the melanoma antigen, gp100. Cancer 2006, 106:890-899.

15. Yamshchikov GV, Barnd DL, Eastham S, Galavotti H, Patterson JW, Deacon DH, Teates D, Neese P, Grosh WW, Petroni G, et al: Evaluation of peptide vaccine immunogenicity in draining lymph nodes and peripheral blood of melanoma patients. Int J Cancer 2001, 92:703-711.

16. Slingluff CL Jr, Yamshchikov GV, Hogan KT, Hibbitts SC, Petroni GR, Bissonette EA, Patterson JW, Neese PY, Grosh WW, Chianese-Bullock KA, et al: Evaluation of the sentinel immunized node for immune monitoring of cancer vaccines. Ann Surg Oncol 2008, 15:3538-3549.

17. Slingluff CL Jr, Petroni GR, Yamshchikov GV, Hibbitts S, Grosh WW, Chianese-Bullock KA, Bissonette EA, Barnd DL, Deacon DH, Patterson JW, et al: Immunologic and clinical outcomes of vaccination with a multiepitope melanoma peptide vaccine plus low-dose interleukin-2 administered either concurrently or on a delayed schedule. J Clin Oncol 2004, 22:4474-4485.

18. Chianese-Bullock KA, Pressley J, Garbee C, Hibbitts S, Murphy C, Yamshchikov G, Petroni GR, Bissonette EA, Neese PY, Grosh WW, et al: MAGE-A1-, MAGE-A10-, and gp100-derived peptides are immunogenic when combined with granulocyte-macrophage colony-stimulating factor and montanide ISA-51 adjuvant and administered as part of a multipeptide vaccine for melanoma. J Immunol 2005, 174:3080-3086.

19. Slingluff CL Jr, Petroni GR, Chianese-Bullock KA, Smolkin ME, Hibbitts S, Murphy C, Johansen N, Grosh WW, Yamshchikov GV, Neese PY, et al: Immunologic and clinical outcomes of a randomized phase II trial of two multipeptide vaccines for melanoma in the adjuvant setting. Clin Cancer Res 2007, 13:6386-6395.

20. Diggle P, Liang K-Y, Zeger SL: Analysis of longitudinal data Oxford New York: Clarendon Press; Oxford University Press 1994.

21. Nestle FO, Alijagic S, Gilliet M, Sun Y, Grabbe S, Dummer R, Burg G, Schadendorf D: Vaccination of melanoma patients with peptide- or tumor lysate-pulsed dendritic cells. Nat Med 1998, 4:328-332.

22. Nakai N, Asai J, Ueda E, Takenaka H, Katoh N, Kishimoto S: Vaccination of Japanese patients with advanced melanoma with peptide, tumor lysate or both peptide and tumor lysate-pulsed mature, monocyte-derived dendritic cells. J Dermatol 2006, 33:462-472.

23. de Vries IJ, Bernsen MR, Lesterhuis WJ, Scharenborg NM, Strijk SP, Gerritsen MJ, Ruiter DJ, Figdor CG, Punt CJ, Adema GJ: Immunomonitoring tumor-specific $T$ cells in delayed-type hypersensitivity skin biopsies after dendritic cell vaccination correlates with clinical outcome. J Clin Oncol 2005, 23:5779-5787.

24. Bedrosian I, Mick R, Xu S, Nisenbaum H, Faries M, Zhang P, Cohen PA, Koski G, Czerniecki BJ: Intranodal administration of peptide-pulsed mature dendritic cell vaccines results in superior CD8+ T-cell function in melanoma patients. J Clin Oncol 2003, 21:3826-3835.

25. Nakai N, Katoh N, Germeraad WT, Kishida T, Ueda E, Takenaka H, Mazda O, Kishimoto S: Immunohistological analysis of peptide-induced delayedtype hypersensitivity in advanced melanoma patients treated with melanoma antigen-pulsed mature monocyte-derived dendritic cell vaccination. J Dermatol Sci 2009, 53:40-47.

26. Steinman RM, Banchereau J: Taking dendritic cells into medicine. Nature 2007, 449:419-426.

27. Dhodapkar MV, Dhodapkar KM, Palucka AK: Interactions of tumor cells with dendritic cells: balancing immunity and tolerance. Cell Death Differ 2008, 15:39-50.
28. Wells JW, Cowled CJ, Farzaneh F, Noble A: Combined triggering of dendritic cell receptors results in synergistic activation and potent cytotoxic immunity. J Immunol 2008, 181:3422-3431.

29. Finotto $S$, Glimcher $L: T$ cell directives for transcriptional regulation in asthma. Springer Semin Immunopathol 2004, 25:281-294.

30. Slingluff CL Jr, Yamshchikov G, Neese P, Galavotti H, Eastham S, Engelhard VH, Kittlesen D, Deacon D, Hibbitts S, Grosh WW, et al: Phase I trial of a melanoma vaccine with gp100(280-288) peptide and tetanus helper peptide in adjuvant: immunologic and clinical outcomes. Clin Cancer Res 2001, 7:3012-3024.

31. Ahmadzadeh M, Felipe-Silva A, Heemskerk B, Powell DJ Jr, Wunderlich JR, Merino MJ, Rosenberg SA: FOXP3 expression accurately defines the population of intratumoral regulatory $T$ cells that selectively accumulate in metastatic melanoma lesions. Blood 2008, 112:4953-4960.

32. Roncador G, Brown PJ, Maestre L, Hue S, Martinez-Torrecuadrada JL, Ling KL, Pratap S, Toms C, Fox BC, Cerundolo V, et al: Analysis of FOXP3 protein expression in human $C D 4+C D 25+$ regulatory $T$ cells at the single-cell level. Eur J Immunol 2005, 35:1681-1691.

33. Walker MR, Kasprowicz DJ, Gersuk VH, Benard A, Van Landeghen M, Buckner JH, Ziegler SF: Induction of FoxP3 and acquisition of T regulatory activity by stimulated human CD4+CD25- T cells. J Clin Invest 2003, 112:1437-1443.

34. Morgan ME, van Bilsen JH, Bakker AM, Heemskerk B, Schilham MW, Hartgers FC, Elferink BG, van der Zanden L, de Vries RR, Huizinga TW, et al: Expression of FOXP3 mRNA is not confined to CD4+CD25+ T regulatory cells in humans. Hum Immunol 2005, 66:13-20.

35. Walker MR, Carson BD, Nepom GT, Ziegler SF, Buckner JH: De novo generation of antigen-specific CD4+CD25+ regulatory $T$ cells from human CD4+CD25- cells. Proc Natl Acad Sci USA 2005, 102:4103-4108.

36. Klemke CD, Fritzsching B, Franz B, Kleinmann EV, Oberle N, Poenitz N, Sykora J, Banham AH, Roncador G, Kuhn A, et al: Paucity of FOXP3+ cells in skin and peripheral blood distinguishes Sezary syndrome from other cutaneous T-cell lymphomas. Leukemia 2006, 20:1123-1129.

37. Curiel TJ, Coukos G, Zou L, Alvarez X, Cheng P, Mottram P, EvdemonHogan M, Conejo-Garcia JR, Zhang L, Burow M, et al: Specific recruitment of regulatory $\mathrm{T}$ cells in ovarian carcinoma fosters immune privilege and predicts reduced survival. Nat Med 2004, 10:942-949.

38. Poulter LW, Seymour GJ, Duke O, Janossy G, Panayi G: Immunohistological analysis of delayed-type hypersensitivity in man. Cell Immunol 1982, 74:358-369.

39. Takemura S, Braun A, Crowson C, Kurtin PJ, Cofield RH, O'Fallon WM, Goronzy JJ, Weyand CM: Lymphoid neogenesis in rheumatoid synovitis. J Immunol 2001, 167:1072-1080.

40. Ayyoub M, Monsarrat B, Mazarguil H, Gairin JE: Analysis of the degradation mechanisms of MHC class I-presented tumor antigenic peptides by high performance liquid chromatography/electrospray ionization mass spectrometry: application to the design of peptidase-resistant analogs. Rapid Commun Mass Spectrom 1998, 12:557-564.

41. Melief CJ, van der Burg SH: Immunotherapy of established (pre)malignant disease by synthetic long peptide vaccines. Nat Rev Cancer 2008, 8:351-360.

42. Speetjens FM, Kuppen PJ, Welters MJ, Essahsah F, Voet van den Brink AM, Lantrua MG, Valentijn AR, Oostendorp J, Fathers LM, Nijman HW, et al: Induction of p53-specific immunity by a p53 synthetic long peptide vaccine in patients treated for metastatic colorectal cancer. Clin Cancer Res 2009, 15:1086-1095.

43. Leffers N, Lambeck AJ, Gooden MJ, Hoogeboom BN, Wolf R, Hamming IE, Hepkema BG, Willemse PH, Molmans BH, Hollema $H$, et al: Immunization with a P53 synthetic long peptide vaccine induces P53-specific immune responses in ovarian cancer patients, a phase II trial. Int J Cancer 2009, 125:2104-2113.

44. Glenn GM, Taylor DN, Li X, Frankel S, Montemarano A, Alving CR: Transcutaneous immunization: a human vaccine delivery strategy using a patch. Nat Med 2000, 6:1403-1406.

45. Shi Z, Curiel DT, Tang DC: DNA-based non-invasive vaccination onto the skin. Vaccine 1999, 17:2136-2141.

46. Guebre-Xabier M, Hammond SA, Ellingsworth LR, Glenn GM: Immunostimulant patch enhances immune responses to influenza virus vaccine in aged mice. J Virol 2004, 78:7610-7618. 
47. Vogt A, Mahe B, Costagliola D, Bonduelle O, Hadam S, Schaefer G, Schaefer H, Katlama C, Sterry W, Autran B, et al: Transcutaneous antiinfluenza vaccination promotes both CD4 and CD8 $\mathrm{T}$ cell immune responses in humans. J Immunol 2008, 180:1482-1489.

48. Kenney RT, Frech SA, Muenz LR, Villar CP, Glenn GM: Dose sparing with intradermal injection of influenza vaccine. N Engl J Med 2004, 351:2295-2301.

49. Rosenberg SA, Sherry RM, Morton KE, Scharfman WJ, Yang JC, Topalian SL, Royal RE, Kammula U, Restifo NP, Hughes MS, et al: Tumor progression can occur despite the induction of very high levels of self/tumor antigenspecific CD8+ T cells in patients with melanoma. J Immunol 2005, 175:6169-6176.

50. Slingluff $C L$ Jr, Petroni GR, Olson W, Czarkowski A, Grosh WW, Smolkin M, Chianese-Bullock KA, Neese PY, Deacon DH, Nail C, et al: Helper T-cell responses and clinical activity of a melanoma vaccine with multiple peptides from MAGE and melanocytic differentiation antigens. $J$ Clin Oncol 2008, 26:4973-4980.

doi:10.1186/1479-5876-8-79

Cite this article as: Schaefer et al:: Dynamic changes in cellular infiltrates with repeated cutaneous vaccination: a histologic and immunophenotypic analysis. Journal of Translational Medicine 2010 8:79.

\section{Submit your next manuscript to BioMed Central and take full advantage of:}

- Convenient online submission

- Thorough peer review

- No space constraints or color figure charges

- Immediate publication on acceptance

- Inclusion in PubMed, CAS, Scopus and Google Scholar

- Research which is freely available for redistribution

Submit your manuscript at www.biomedcentral.com/submit 